\title{
Impact of inspiratory muscle training in patients with COPD: what is the evidence?
}

\author{
R. Gosselink*,", J. De Vos*\#, S.P. van den Heuvel", J. Segers*,", \\ M. Decramer*\# and G. Kwakkel ${ }^{+}$
}

ABSTRACT: A meta-analysis including 32 randomised controlled trials on the effects of inspiratory muscle training (IMT) in chronic obstructive pulmonary disease (COPD) patients was performed. Overall and subgroup analyses with respect to training modality (strength or endurance training, added to general exercise training) and patient characteristics were performed. Significant improvements were found in maximal inspiratory muscle strength $\left(P I, \max ;+13 \mathrm{cmH}_{2} \mathrm{O}\right)$, endurance time (+261 s), 6- or 12-min walking distance (+32 and $+85 \mathrm{~m}$ respectively) and quality of life (+3.8 units). Dyspnoea was significantly reduced (Borg score -0.9 point; Transitional Dyspnoea Index +2.8 units). Endurance exercise capacity tended to improve, while no effects on maximal exercise capacity were found. Respiratory muscle endurance training revealed no significant effect on PI,max, functional exercise capacity and dyspnoea. IMT added to a general exercise programme improved $P$ I,max significantly, while functional exercise capacity tended to increase in patients with inspiratory muscle weakness $\left(P \mathrm{I}, \max <60 \mathrm{cmH}_{2} \mathrm{O}\right)$.

IMT improves inspiratory muscle strength and endurance, functional exercise capacity, dyspnoea and quality of life. Inspiratory muscle endurance training was shown to be less effective than respiratory muscle strength training. In patients with inspiratory muscle weakness, the addition of IMT to a general exercise training program improved $P_{\text {I,max }}$ and tended to improve exercise performance.

KEYWORDS: Meta-analysis, muscle training, respiratory muscles, systematic review

$\mathbf{R}$ espiratory muscle weakness is observed in chronic obstructive pulmonary disease (COPD) patients [1, 2] and contributes to hypercapnia [3], dyspnoea [4,5], nocturnal oxygen desaturation [6] and reduced walking distance [7]. During exercise it has been shown that diaphragm work is increased in COPD [8] and COPD patients use a larger proportion of the maximal inspiratory pressure $(P \mathrm{I}, \max )$ than healthy subjects [9]. This pattern of breathing is closely related to the dyspnoea sensation during exercise [9] and might potentially induce respiratory muscle fatigue. However, diaphragmatic fatigue was not demonstrated after exhaustive exercise [10]. Studies in patients with COPD have shown natural adaptations of the diaphragm to greater oxidative capacity and resistance to fatigue [11-13]. The abovementioned considerations gave conflicting arguments to the rationale of respiratory muscle training in COPD. Current guidelines [14, 15] and meta-analyses [16-20] are not undisputedly positive on the application of inspiratory muscle training (IMT). From meta-analyses it is clear that IMT increases inspiratory muscle strength and endurance, and decreases dyspnoea. However, exercise performance and quality of life did not improve significantly $[18,20,21]$. The addition of IMT to a general exercise programme did not improve exercise performance [20]. Furthermore, differences in effects of resistance and endurance training were never analysed, while patient characteristics relevant for favourable effects of IMT have not been identified so far. Finally, many randomised controlled trials have been published since our previous meta-analysis, offering more input for more extensive analysis. The aim of the

\section{AFFILIATIONS}

*Faculty of Kinesiology and Rehabilitation Sciences, Katholieke Universiteit Leuven,

\#Respiratory Rehabilitation and Respiratory Division, University Hospitals KU Leuven, Leuven, Belgium.

'Dutch Institute of Allied Health Care, Amersfoort, and

${ }^{+}$Research Institute MOVE, VU University Medical Center Amsterdam and Rudolf Magnus Institute of Neuroscience, University Medical Center Utrecht, Utrecht, The Netherlands.

CORRESPONDENCE

R. Gosselink

University Hospitals KU Leuven Respiratory Rehabilitation and Respiratory Division

Herestraat 49

B3000 Leuven

Belgium

E-mail: Rik.Gosselink@

faber.kuleuven.be

Received:

Feb 282010

Accepted after revision:

May 252010 
present meta-analysis is to: 1) investigate the effects of IMT as stand-alone therapy or added to general exercise training; 2) identify patient characteristics associated with favourable effects of IMT; and 3) identify the most appropriate training modality in terms of strength or endurance training for IMT.

\section{METHODS}

A detailed description of the methods section is available in the online supplement.

\section{Study identification and selection}

We performed an update and extension of the meta-analysis from our group [21]. For the current meta-analysis, an additional search up to May 2009 was performed independently by two reviewers (J. De Vos and S.P. van den Heuvel). Studies had to satisfy the following criteria to be included for further analysis: 1) true experimentation (i.e. randomised or quasirandomised controlled trial); 2) COPD patients with pulmonary function tests; 3) IMT at an intensity of $\geqslant 30 \%$ PI,max [22] or respiratory muscle endurance training in a controlled manner; 4) outcomes should have been described in terms of inspiratory muscle strength $(P \mathrm{I}, \mathrm{max})$, inspiratory muscle endurance, dyspnoea rating, 6- or 12-min walking distance (6MWD or 12MWD) and/or health-related quality of life (HRQoL). In contrast to all previous meta-analyses, no language restrictions were used. The methodological quality of each included study was scored using a modification of the framework for methodological quality as previously described [16, 21].

\section{Meta-analysis}

The effect size $g_{i}$ (Hedges' g) of each individual study was calculated by the difference between the means of the experimental and the control groups before and after the intervention divided by the average population standard deviation $\left(\mathrm{SD}_{\mathrm{i}}\right)$. If data were not in a form suitable for quantitative pooling, we contacted trial authors for additional information. The analyses were initially performed for the total set of included studies. Subsequently, effectiveness was compared between inspiratory muscle strength (threshold or resistive) and endurance training and the addition of IMT to general exercise reconditioning (GER) was analysed. The homogeneity test Cochrane Q-statistic (Q-test) of each set of effect sizes was calculated to determine whether studies shared a common effect size of which the variance could be explained by sampling error alone. A minimum of three studies was set for pooling in order to perform a quantitative analysis of the studies. However, the Q-test is known to be poor at detecting true heterogeneity among studies as significant [23], in particular when a small number of studies is included and the power of the test is low. Therefore, the $\mathrm{I}^{2}$-statistic was calculated to determine heterogeneity and consider further sensitivity analysis. Heterogeneity was defined if $\mathrm{I}^{2}$ was beyond $50 \%$ [23].

On the basis of existing literature, we hypothesised the following potential effect modifiers: 1) patient characteristics $\left(P \mathrm{I}\right.$,max $\leqslant 60$ or $>60 \mathrm{cmH}_{2} \mathrm{O}$, forced expiratory volume in $1 \mathrm{~s}$, and arterial oxygen $\left(\mathrm{Pa}, \mathrm{O}_{2}\right)$ and carbon dioxide $\left(\mathrm{Pa}_{\mathrm{a}} \mathrm{CO}_{2}\right)$ tension); 2) training load; 3) training modality (strength or endurance training) and 4) duration of the training programme $(<2$ or $>2$ months of training). The influence of having sham or no sham control group was considered in a separate analysis. To determine possible association between, on the one hand, methodological quality of individual studies and, on the other hand, individual effect size, a Spearman rank correlation coefficient was calculated. Since small studies will typically show more variability among effect sizes than larger studies and small studies with insignificant effects are less likely published, a funnel plot of sample size versus estimated effect size was derived for included studies for PI,max (fig. S2 in the online supplementary material). For all outcome variables, the critical value for rejecting $\mathrm{H}_{0}$ was set two-tailed at $\mathrm{p}=0.05$. On the basis of the classification by Cohen, effect sizes $<0.2$ were classified as small, those from 0.2 to 0.8 as medium, and those $>0.8$ as large [24].

\section{RESULTS}

\section{Critical review}

A total of 129 new studies (time frame 2000-2009) were retrieved from the literature search and 111 studies were excluded (see online supplementary material and fig. S1 for details). This resulted in 18 new eligible studies [25-42] and 14 studies [43-56] published before 2000 from the previous metaanalysis [21]. Accordingly, a total of 32 samples including 830 COPD patients were eligible for meta-analysis. Characteristics of the individual studies are provided in table S3 in the online supplementary material. The overall treatment group consisted of 430 patients (318 males and 112 females) and the control group of 400 . The main patient characteristics of the overall treatment group are included in table S4 in the online supplementary material. An overview of the different subgroups studied is provided in table S3 in the online supplementary material. The methodological quality score varied from $30-83 \%$ (median 59\%) of the maximum score (table S2 in the online supplementary material) and did not significantly relate to the effect size observed in the studies.

\section{Inspiratory muscle strength}

The meta-analysis for inspiratory muscle strength demonstrated a significant effect with an increase of $13 \mathrm{cmH}_{2} \mathrm{O}$ (summary effect size (SES) $0.68,95 \%$ CI 0.54-0.82; p<0.001) in the treatment group compared with the control group (table 1 and fig. 1). The homogeneity test, however, showed borderline heterogeneity $\left(\mathrm{I}^{2}=46 \%\right)$ in the sample, but a random effects model showed similar results (SES 0.73, 95\% CI 0.53-0.93; $\left.\mathrm{I}^{2}=37 \%, \mathrm{p}<0.001\right)$. As shown in figure 1 , the observed heterogeneity between studies was mainly due to a study of Di MAMBro et al. [28]. Subsequent sensitivity analysis without the study of Di MAMBRo et al. [28] showed a homogenous SES, which was, again, highly significant $(\mathrm{p}<0.001)$. Both studies with sham $(n=23)$ or no sham $(n=9)$ control intervention revealed similar significant improvements in PI,max.

Subgroup analysis of inspiratory muscle strength training $(k=28)$ and studies investigating inspiratory muscle endurance training $(\mathrm{k}=3)$ revealed that the former remained significant (SES 0.75, 95\% CI 0.57-0.87; +13 $\mathrm{cmH}_{2} \mathrm{O} ; \mathrm{I}^{2}=45 \%, \mathrm{p}<0.001$ ) whereas the latter lost statistical significance (SES 0.19, 95\% CI $-0.22-0.59 ; \mathrm{I}^{2}=0 \%, \mathrm{p}=0.36$ ) (fig. 1). No difference was found between threshold and resistive training. The subgroup analysis of GER+IMT versus GER showed a homogeneous and significant improvement in inspiratory muscle strength (SES 0.69, 95\% CI $0.42-0.96 ; \mathrm{I}^{2}=1 \%, \mathrm{p}<0.001$ ) (fig. 2) in the 


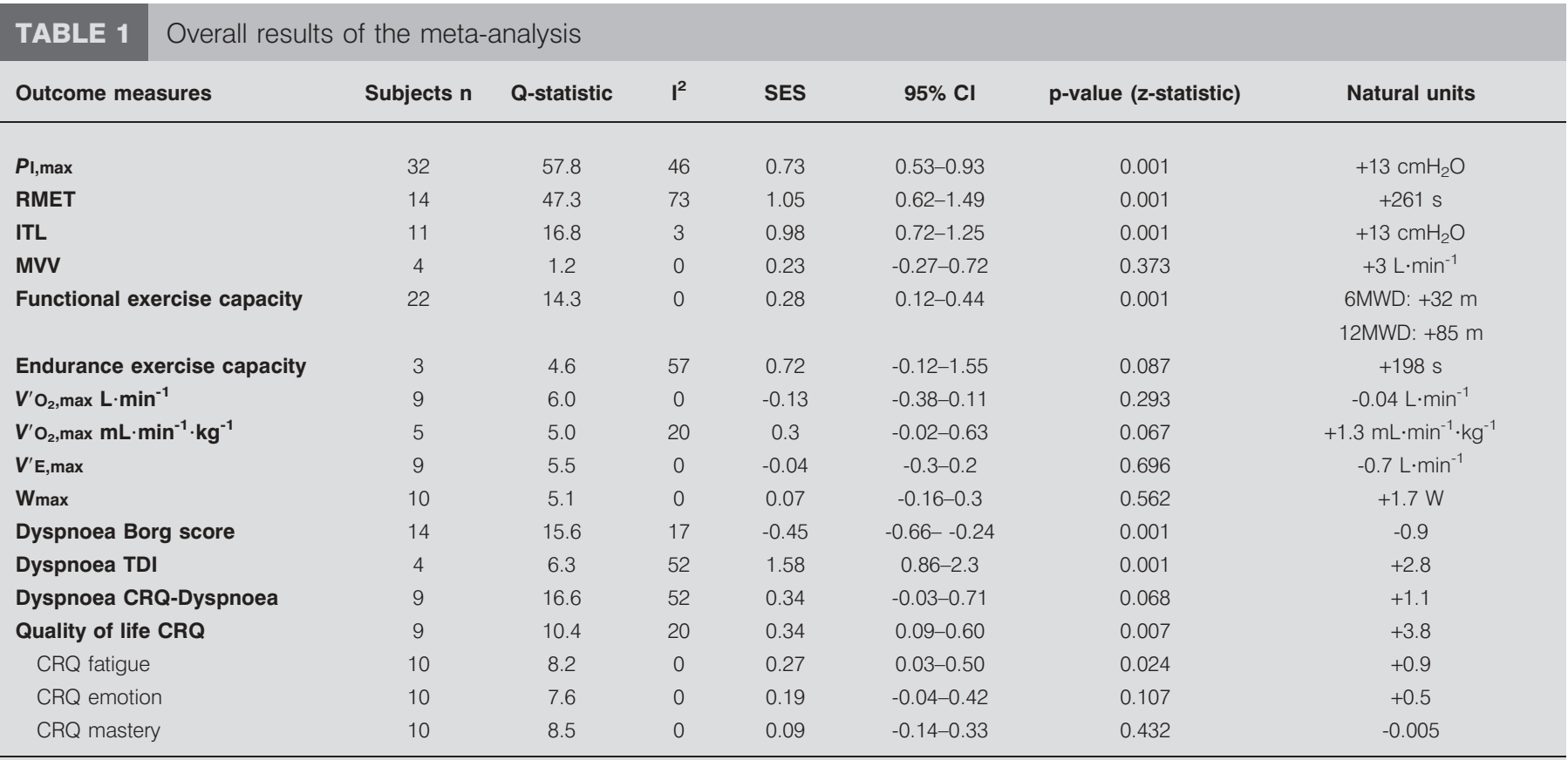

$\mathrm{n}=32$. SES: summary effect size; PI,max: maximal inspiratory pressure; RMET: respiratory muscle endurance test: ITL: incremental threshold loading; MVV: maximal voluntary ventilation; $V^{\prime} \mathrm{O}_{2}$,max: maximal oxygen uptake; $V^{\prime} E$,max: maximal minute ventilation; Wmax: maximal power output; TDI: transition dyspnoea index; $C R Q$ : chronic respiratory questionnaire.

training group compared with the control group. Further analysis of the studies without inspiratory muscle weakness $(\mathrm{k}=5)$ and studies with inspiratory muscle weakness $(\mathrm{k}=4)$ demonstrated no significance in the former (SES 0.42, 95\% CI $\left.-0.01-0.85 ; \mathrm{I}^{2}=0 \%, \mathrm{p}=0.06\right)$, while the latter remained significant (SES 0.87, 95\% CI 0.52-1.21; $\mathrm{I}^{2}=0 \%, \mathrm{p}<0.001$ ).

A significant inverse association was found between baseline $\mathrm{Pa}_{\mathrm{a}} \mathrm{O}_{2}$ and changes in $\mathrm{P} \mathrm{I}, \max (\mathrm{r}=-0.75, \mathrm{p}<0.01$; fig. S3, lower panel, in the online supplementary material). In addition, baseline $\mathrm{Pa}, \mathrm{CO}_{2}$ correlated significantly with changes in $P \mathrm{I}$,max $(\mathrm{r}=0.61, \mathrm{p}<0.05$; fig. S3, upper panel, in the online supplementary material), whereas length of the training period and training load did not influence the change in PI,max.

\section{Inspiratory muscle endurance}

Two meta-analyses for measures of inspiratory muscle endurance were conducted. A significant and homogeneous improvement was found for incremental threshold loading $\left(+13 \mathrm{cmH}_{2} \mathrm{O}\right.$; SES 0.98, 95\% CI 0.72-1.25; $\left.\mathrm{I}^{2}=3 \%, \mathrm{p}<0.001\right)$ in favour of the training group (table 1 ). Both studies with sham $(n=8)$ or no sham $(n=3)$ control intervention revealed similar significant improvements in endurance load. The analysis for respiratory muscle endurance test (RMET) also produced a significant (+261 s; SES 0.82, 95\% CI 0.60-1.04; $\mathrm{p}<0.001$ ), but heterogeneous $\left(\mathrm{I}^{2}=73 \%\right)$ result. After applying a random effects model, significance remained (SES 1.05, 95\% CI 0.62$1.49 ; \mathrm{p}<0.001)$. Both studies with sham $(n=9)$ or no sham $(n=5)$ control intervention revealed similar significant improvements in endurance time.

For subgroup analysis the sample was divided into studies that applied inspiratory muscle strength training $(\mathrm{k}=11)$ and endurance training $(\mathrm{k}=3)$. Both samples were heterogeneous $\left(\mathrm{I}^{2}=52 \%\right.$ and $\left.85 \%\right)$; hence, random effects models were applied which demonstrated significant effects in both groups (strength training SES 0.78, 95\% CI 0.4-1.15; $\mathrm{p}<0.0001$; endurance training SES 1.95, 95\% CI 0.63-3.26; p<0.01). In the strength training group, no difference was found between outcomes for threshold and resistive training devices. In the group with strength training, a significant, homogeneous effect in favour of the IMT group was observed in studies with inspiratory muscle weakness ( $k=5$, SES $0.34,95 \%$ CI $0.04-0.64$; $\left.\mathrm{I}^{2}=42 \%, \mathrm{p}<0.05\right)$. Studies without inspiratory muscle weakness revealed heterogeneous effects $(k=6$, SES 1.15 , 95\% CI 0.73 $1.57 ; \mathrm{I}^{2}=60 \%, \mathrm{p}<0.001$ ), while the random model failed to reach statistical significance. The analysis of RMET in studies adding IMT to GER also showed a significant effect in favour of the IMT group (+242 s, SES $0.98,95 \%$ CI $0.72-1.25 ; \mathrm{I}^{2}=3 \%$, $\mathrm{p}=0.001$ ).

\section{Exercise capacity}

Analysis of functional exercise capacity revealed homogeneous and significant improvement of 6MWD and 12MWD $(+32 \mathrm{~m}$ and $+85 \mathrm{~m}$, respectively) (SES $0.28,95 \%$ CI $0.12-0.44 ; \mathrm{I}^{2}=0 \%$, $\mathrm{p}<0.001)$ in the training group compared with the control group. When comparing inspiratory muscle strength $(k=19)$ and endurance training $(k=3)$, a significant effect was found in favour of the treatment group following strength training (SES $0.29,95 \%$ CI $0.11-0.47 ; \mathrm{p}<0.01)$, but not for endurance training (SES 0.21, 95\% CI -0.19-0.62; $\mathrm{p}=0.29$ ) (fig. 3). Further analysis showed that the group receiving resistive training $(k=3)$ just lost significance (SES 0.41, 95\% CI -0.03-0.85; $\mathrm{p}=0.06$ ), while the threshold group $(\mathrm{k}=16)$ remained significant (SES 0.27, $95 \%$ CI $0.07-0.46 ; \mathrm{p}<0.01)$. Studies with sham control $(\mathrm{n}=17)$ 


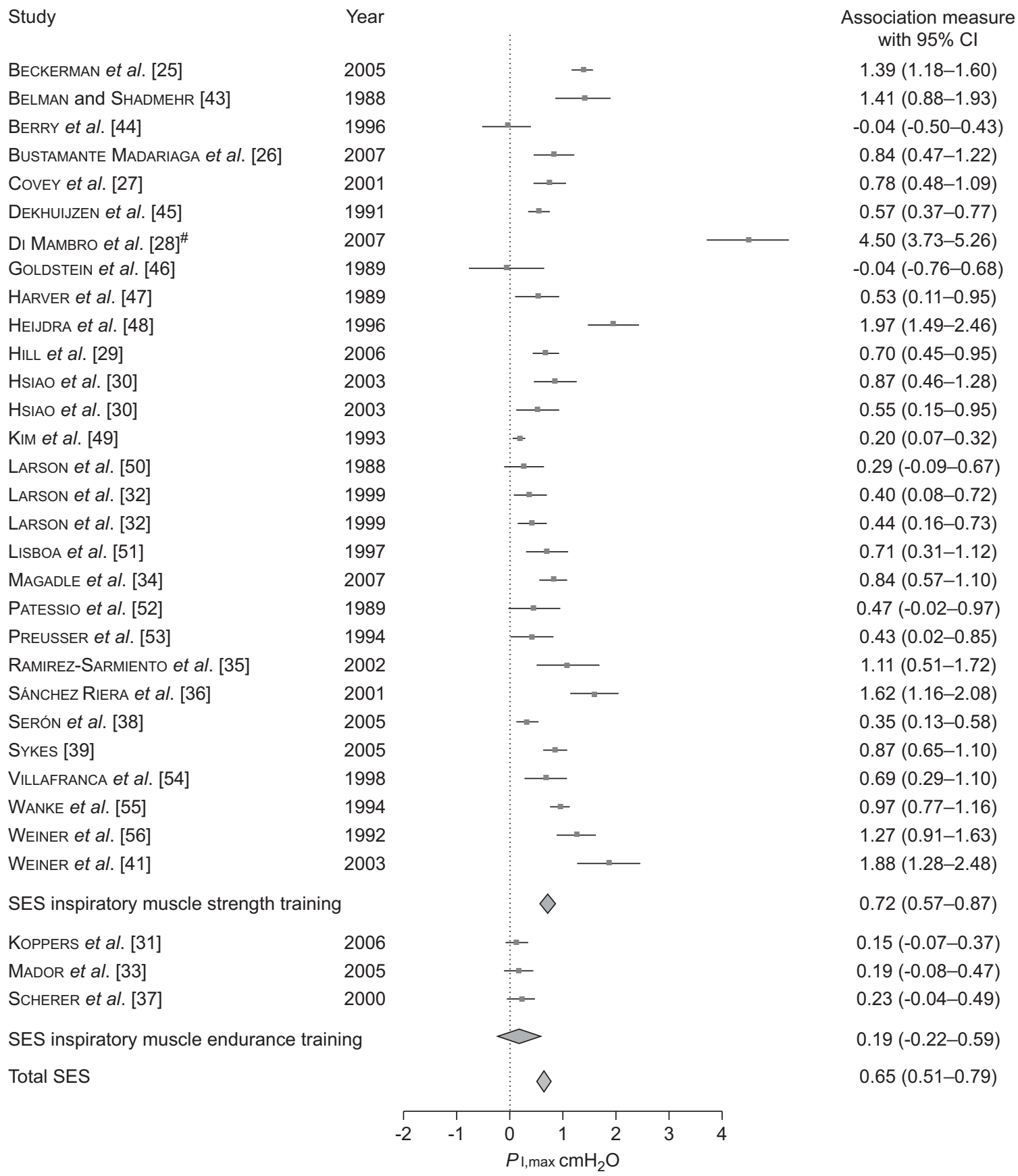

FIGURE 1. Effect of inspiratory muscle strength and endurance training on maximal inspiratory strength (Pl,max). \#: excluded from the analyses.

revealed significant improvements in functional exercise performance (SES 0.30, 95\% CI $0.11-0.49 ; \mathrm{I}^{2}=0 \%, \mathrm{p}<0.001$ ), but studies without sham control intervention $(n=5)$ failed to reach statistical significance $(\mathrm{p}=0.09)$. The subgroup analysis of studies applying IMT as a mono-intervention found a significant improvement in favour of the IMT group (SES 0.27, 95\% CI 0.07-0.46; $\mathrm{p}<0.01$ ), while studies adding IMT to GER $(k=7)$ were marginally significant (SES 0.29 , 95\% CI -0.004$0.58 ; \mathrm{p}=0.05)$. Subdividing this analysis into a group of studies with $(\mathrm{k}=3)$ and a group without $(\mathrm{k}=4)$ inspiratory muscle weakness, resulted in a significant result for the former (SES
$0.51,95 \%$ CI $0.10-0.91 ; \mathrm{p}<0.05$ ), but not for the latter (SES 0.05, $95 \%$ CI -0.37-0.47; $\mathrm{p}=0.82$ ) (fig. 4). However, the muscle weakness subgroup showed heterogeneity and just failed to reach statistical significance (SES 0.60, 95\% CI -0.08-1.29; $\mathrm{p}=0.08$ ) in the random effects model. The analysis of endurance exercise capacity produced a significant $(k=3$, SES 0.80 , 95\% CI 0.32-1.37; +198 s; $\mathrm{p}<0.01$ ), though not homogeneous $\left(\mathrm{I}^{2}=57 \%\right)$, improvement in the IMT group compared with the control group. The subsequent random effects model did not reach statistical significance (SES 0.72, 95\% CI -0.12$1.55 ; \mathrm{p}=0.08)$. 


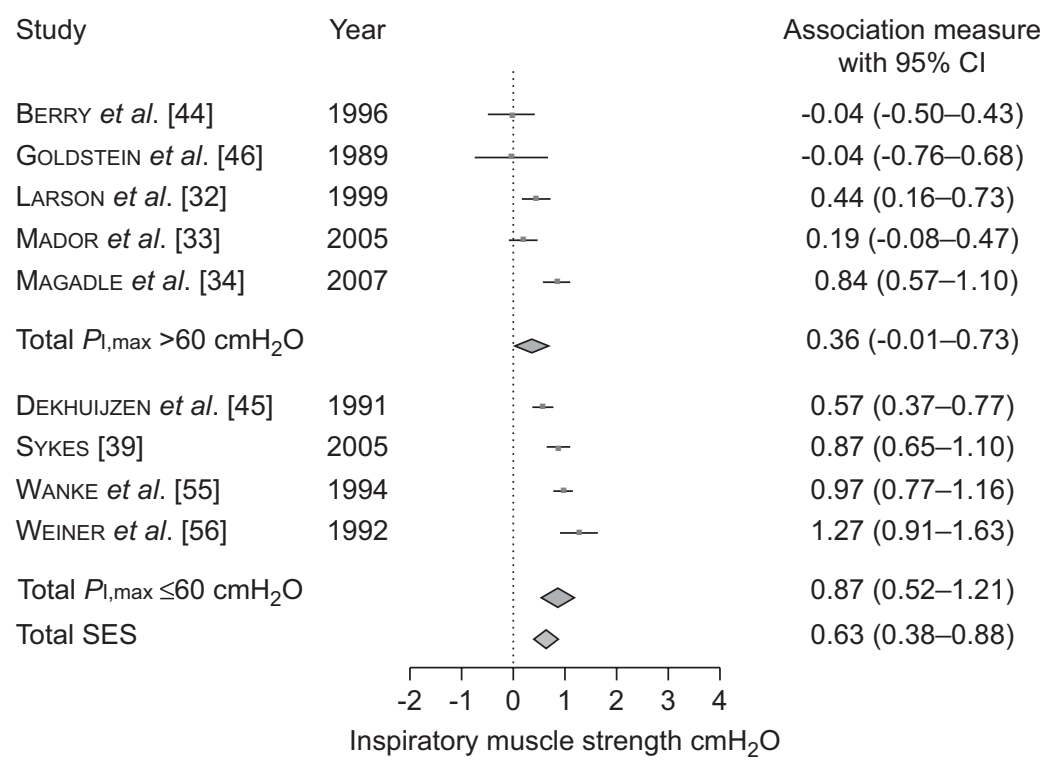

FIGURE 2. Effect of general exercise reconditioning (GER) plus inspiratory muscle training versus GER alone on inspiratory muscle strength. PI,max: maximal inspiratory pressure.

Results for maximal power output (Wmax) on the bicycle test $\left(\mathrm{k}=10\right.$, SES $0.07,95 \%$ CI $\left.-0.16-0.30 ;+2 \mathrm{~W} ; \mathrm{I}^{2}=0 \%, \mathrm{p}=0.56\right)$, maximal minute ventilation $\left(V^{\prime} \mathrm{E}, \max \right)(\mathrm{k}=9$, SES $-0.04,95 \% \mathrm{CI}$ $\left.-0.30-0.21 ;-0.7 \mathrm{~L} \cdot \mathrm{min}^{-1} ; \mathrm{I}^{2}=0 \%, \mathrm{p}=0.69\right)$, maximal oxygen uptake $\left(V^{\prime} \mathrm{O}_{2}, \max \right)$ in $\mathrm{L} \cdot \mathrm{min}^{-1}(\mathrm{k}=9$, SES $-0.13,95 \%$ CI -0.38 $\left.0.11 ; 0.04 \mathrm{~L} \cdot \mathrm{min}^{-1} ; \mathrm{I}^{2}=0 \%, \mathrm{p}=0.29\right)$ and oxygen uptake in $\mathrm{mL}$. $\min ^{-1} \cdot \mathrm{kg}^{-1}\left(\mathrm{k}=5\right.$, SES $0.30,95 \%$ CI $-0.02-0.63 ; 1.3 \mathrm{~mL} \cdot \mathrm{min}^{-1} \cdot \mathrm{kg}^{-1}$; $\left.\mathrm{I}^{2}=20 \%, \mathrm{p}=0.06\right)$ revealed no significant overall effect. Subgroup analyses for $W_{\max } V^{\prime} \mathrm{E}$,max and $V^{\prime} \mathrm{O}_{2}$, max revealed no significant effect for either of the subgroups IMT versus control and IMT+GER versus GER. The analysis conducted for maximal voluntary ventilation (MVV) did show a homogenous $\left(\mathrm{I}^{2}=0 \%\right)$ and nonsignificant summary effect (SES $0.23,95 \% \mathrm{CI}$ $\left.-0.27-0.72 ;+3 \mathrm{~L} \cdot \mathrm{min}^{-1} ; \mathrm{p}=0.37\right)$.

\section{Dyspnoea}

Three analyses containing measures of dyspnoea (Borg score, transition dyspnoea index (TDI) and chronic respiratory questionnaire (CRQ) dyspnoea score) were conducted. A significant and homogeneous $\left(\mathrm{I}^{2}=17 \%\right)$ effect was found for Borg score (SES $-0.45,95 \%$ CI $-0.66--0.24 ;-0.9$ point; $\mathrm{p}<0.0001$ ), favouring the training group. When comparing threshold and resistive training for this measure, the former remained significant (SES $-0.38,95 \%$ CI $-0.62--0.14 ; \mathrm{p}<0.01$ ) while the latter lost significance (SES -0.46, 95\% CI -0.99-0.07; $\mathrm{p}=0.09$ ). Studies with sham $(n=8)$ revealed significant improvements in dyspnoea (SES -0.67, 95\% CI -0.96- -0.40; p <0.0001), but studies without sham control intervention $(n=6)$ were not statistically significant $(p=0.16)$. The analysis conducted for the focal score of the TDI demonstrated a significant, but heterogeneous $\left(\mathrm{I}^{2}=52 \%\right.$ ), effect (SES 1.47, 95\% CI 0.99-1.96; 2.8 points; $\mathrm{p}<0.001$ ) in favour of the treatment group. The result of the random effects model remained significant (SES 1.58, 95\% CI 0.86-2.30; $\mathrm{p}<0.0001)$. Similarly, the analysis conducted for CRQ dyspnoea score showed a significant, but heterogeneous $\left(\mathrm{I}^{2}=52 \%\right.$ ), increase (SES 0.33, 95\% CI 0.07-0.58; 1.1 points; $\mathrm{p}<0.05)$. The random effects model failed to show statistical significance (SES 0.34, 95\% CI -0.03-0.71; $\mathrm{p}=0.06$ ). Subgroup analysis for CRQ dyspnoea in studies that applied inspiratory muscle strength training $(\mathrm{k}=8)$ demonstrated a significant, homogeneous effect (SES $0.45,95 \%$ CI $0.18-0.72$; $\mathrm{p}<0.01$ ) in favour of the IMT group. Studies with sham $(n=4)$ revealed significant improvements in CRQ dyspnoea (SES 0.44, 95\% CI $0.06-0.82 ; p<0.01)$, but studies without sham $(n=5)$ control intervention failed to reach statistical significance $(p=0.08)$. Subgroup analysis for endurance training was not possible, due to the limited number of studies using this outcome $(k=1)$. A subgroup analysis of trials adding IMT to a GER programme showed no significant effects on the Borg dyspnoea score (SES $-0.32,95 \%$ CI $-0.70-0.06 ; p=0.10$ ) and CRQ dyspnoea score (SES $-0.06,95 \%$ CI $-0.78-0.66 ; \mathrm{p}=0.88)$.

\section{Quality of life}

Meta-analysis demonstrated a significant (SES 0.34, 95\% CI $0.09-0.60 ; 3.8$ points; $\mathrm{p}<0.01)$, homogeneous $\left(\mathrm{I}^{2}=23 \%\right)$ improvement in the total score of the CRQ in favour of the IMT group when compared with the control group. Studies with sham $(n=5)$ revealed significant improvements in quality of life (SES $0.40,95 \%$ CI $0.07-0.73$; $<<0.01)$, but studies without sham $(n=4)$ control intervention failed to reach statistical significance $(p=0.08)$. Analysis for the different items of the CRQ scale demonstrated a significant effect on the dyspnoea (see above) and the fatigue scale $(+0.87$ points; $\mathrm{p}<0.05)$ in favour of the IMT group. The analysis for emotion failed to show statistical significance (SES $0.19,95 \%$ CI $-0.04-0.42 ;+0.48$ points; $\mathrm{p}=0.10$ ), while mastery showed no improvement (SES 0.09, 95\% CI $-014-0.33 ;-0.01$ points; $p=0.42$ ). No effects on these items were found when performing the subgroup analysis of IMT+GER versus GER. Meta-analyses could not be performed on other measurements of quality of life (see online supplementary material). 


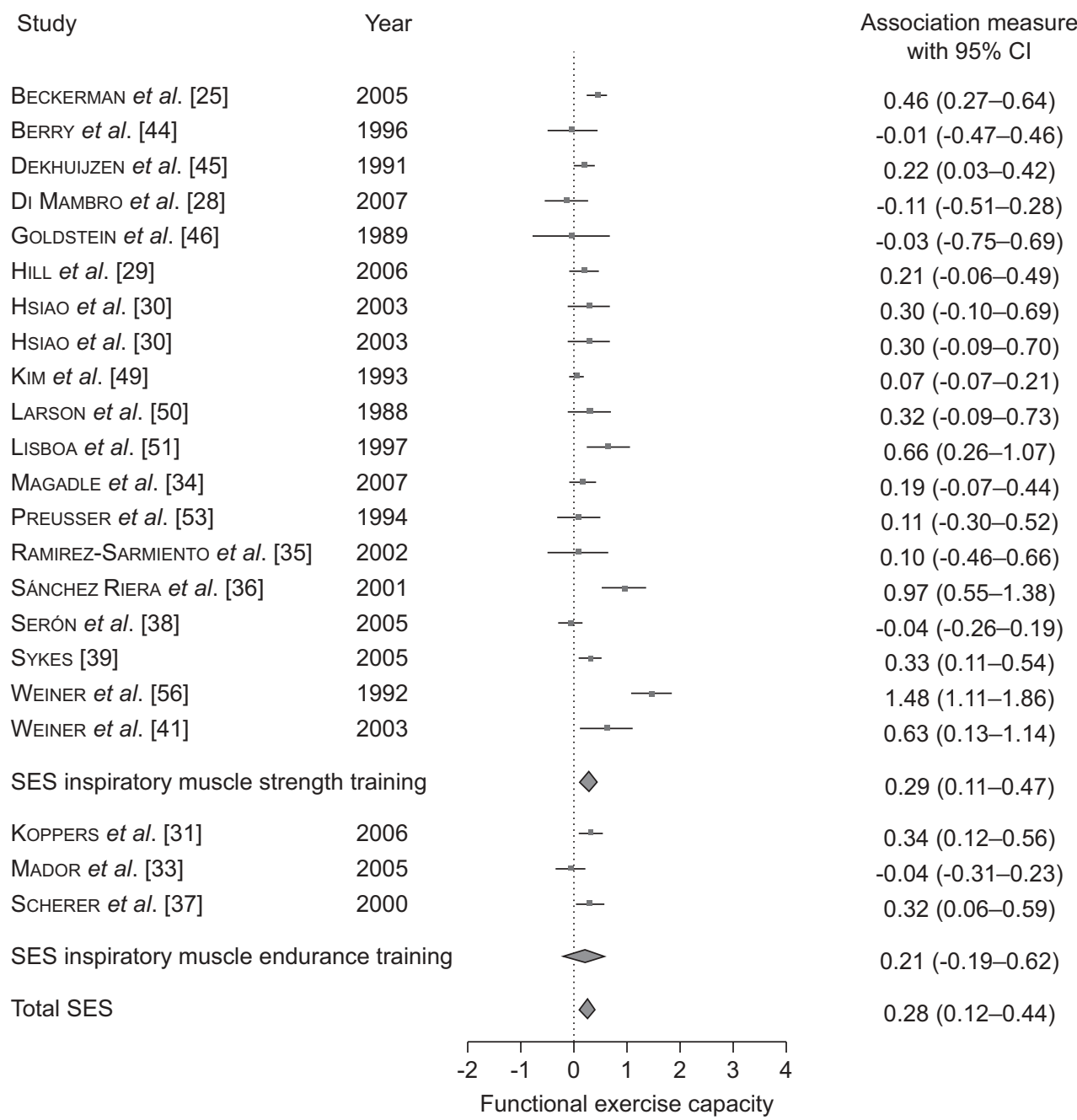

FIGURE 3. Effect of inspiratory strength and endurance training on functional exercise capacity (6-min walk distance).

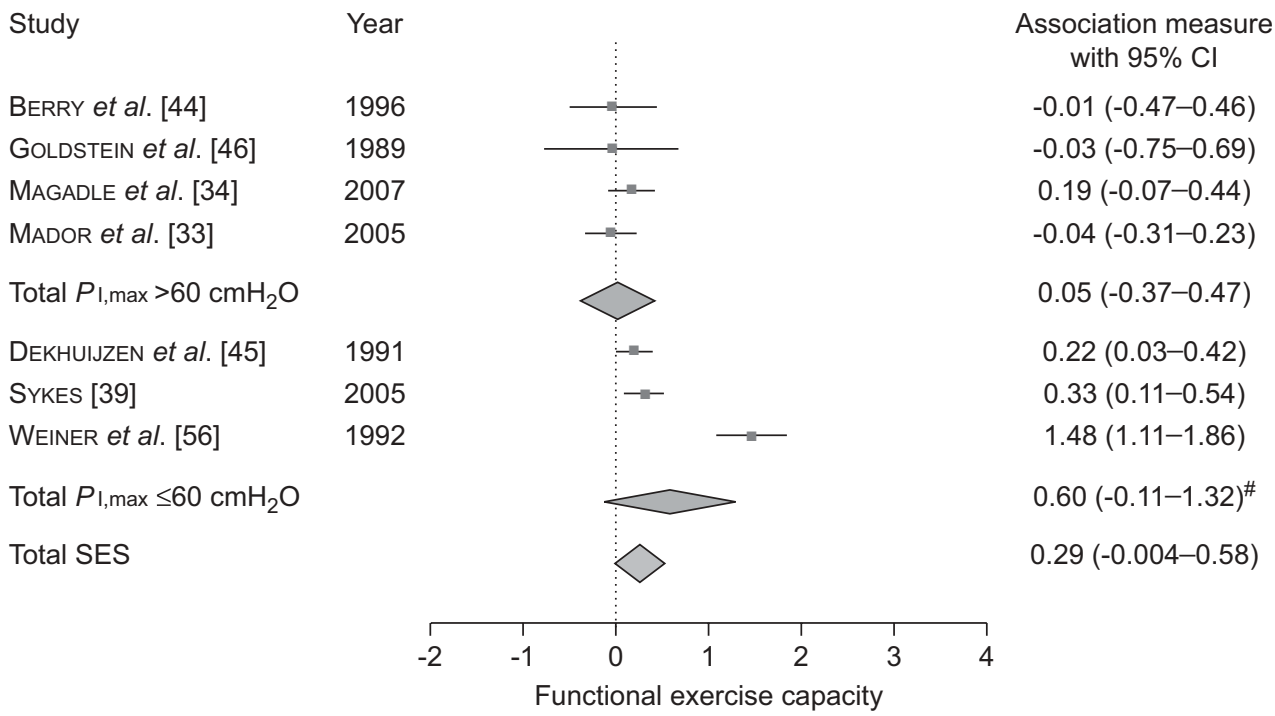

FIGURE 4. Effect of general exercise reconditioning (GER) plus inspiratory muscle training versus GER alone on functional exercise performance. Pl,max: maximal inspiratory pressure. ${ }^{\#}$ : result from random effects model. 


\section{DISCUSSION}

This meta-analysis included 18 more studies and further substantiates the evidence for application of IMT in COPD patients. Statistically significant medium to large effect sizes (mean 0.73) and clinical relevant improvements were observed for inspiratory muscle strength $\left(13 \mathrm{cmH}_{2} \mathrm{O}\right)$ and endurance (261 s), functional exercise capacity (32 m), dyspnoea (2.8 points TDI) and quality of life (3.8 points CRQ). Changes in maximal and endurance exercise capacity failed to reach statistical significance. Inspiratory muscle strength training was superior to endurance training for improving inspiratory muscle strength, functional exercise performance and dyspnoea. Patients with a clear inspiratory muscle weakness and lower $\mathrm{Pa}, \mathrm{O}_{2}$ or higher $\mathrm{Pa}, \mathrm{CO}_{2}$ showed better response to IMT on inspiratory muscle strength and functional exercise capacity than those patients with better preserved respiratory muscle function. The improvement in inspiratory muscle endurance capacity is supported by a study in COPD patients showing significant increases in the proportion of type I fibres and size of type II fibres in the external intercostals after IMT [35]. The addition of IMT to a general exercise training programme resulted, only in patients with inspiratory muscle weakness, in borderline nonsignificant improvement of functional exercise performance.

Although we agree that an appropriately designed randomised controlled trial should be the golden standard to test the hypothesis that IMT is effective in patients with COPD, we should also acknowledge that most randomised controlled trials suffer from insufficient statistical power to underpin the effects of IMT. With that, the strength of a meta-analysis is the ability to combine studies with the same intervention and same outcome "as if" there is one overall study in order to prevent type II error. Therefore, conclusions from meta-analyses are more powerful than from a single randomised controlled trial. A second strength of meta-analysis is the ability to compare individual studies, allowing the identification of possible modifiers and confounders that may have affected claimed effects in order to give recommendations for further research.

Our meta-analysis confirms and debates several findings of the recent meta-analysis by GEDDES et al. [57]. In addition, we provide new data on the choice of training modalities for IMT and patient characteristics relevant for selection of patients. The analysis by GEDDES et al. [57] contained substantially fewer papers than the present meta-analysis. For 6MWD, maximal exercise capacity, dyspnoea Borg and quality of life, their respective analyses contained four, four, four and only two trials, while we reported on 22, 10, 14 and nine papers, respectively. This is, in part, due to inclusion of studies in other languages $(n=2)[26,28]$, studies that added IMT to general exercise training $(n=8)[33,34,39,40,44,45,55,56]$, recent publication $(n=3)[26,28,34]$, and endurance training modality $(n=2)[33,37]$. In addition, we included studies with and without a "sham training" control group. Statistical significance was lost for the analysis (including a very small number of studies) with comparison of IMT with no sham intervention for functional exercise capacity, dyspnoea and quality of life. However, the meta-analysis performed in studies with comparison of IMT with a sham control intervention, the most critical comparison, revealed statistical significant improvements in inspiratory muscle strength and endurance, functional exercise capacity, dyspnoea and quality of life.

The analysis of functional exercise capacity included trials measuring 6MWD, 12MWD and one paper that used the shuttle walk test (SWT) [36]. The analysis showed no heterogeneity and analyses of functional exercise capacity without the data from the SWT did not affect any of the results. The clinical importance of the findings was investigated through transforming the outcomes to natural units. The improvement of $32 \mathrm{~m}$ on the 6MWD was highly significant and within the range of the recently redefined minimal clinical important difference (MCID) of $35 \mathrm{~m}$ [58] and $25 \mathrm{~m}$ [59]. The effects on quality of life (CRQ +3.8 points) and its sub-items did not reach the MCID of 0.5 points per question. The TDI score of 2.8 points clearly crosses the MCID of 1 point [60].

Previous meta-analyses $[20,57]$ reported significant effects on maximal ventilation during exercise and MVV that were not observed in our analyses. However, their analysis on MVV included two reports $[43,47]$, while ours included two extra trials $[44,46]$. Similarly, their analysis on $V^{\prime} E$,max included only two reports [36, 51], while our analysis was based on nine reports $[29,32,33,36,44,45,51,55]$. It is likely that their limited number of studies caused false-positive effects.

\section{Does the choice for inspiratory muscle strength or endurance training matter?}

Three types of inspiratory muscle training, i.e. "inspiratory resistive training", "threshold loading" and "normocapnic hyperpnoea" (NCH) were practised. $\mathrm{NCH}$ is considered "endurance training" since it has high number of repetitions and no additional resistance for 15-20 $\mathrm{min}$ [61, 62]. "Inspiratory resistive breathing" and "threshold loading" are considered a mixture of strength and endurance training, since the number of contractions is low and the inspiratory resistance is relatively high. Subgroup analyses comparing strength and endurance training revealed better effects on inspiratory muscle strength, functional exercise capacity and dyspnoea following strength training. Both modalities of training significantly improved inspiratory muscle endurance, but only strength training was able to significantly improve $P$ I,max and functional exercise capacity. It is, however, difficult to draw firm conclusions, since only three studies investigated the effects of inspiratory muscle endurance training, while 29 trials applied strength training. A head to head comparison between strength and endurance training is needed to substantiate differences in effectiveness.

Subgroup analysis of resistive breathing and threshold training for functional exercise capacity and dyspnoea measured on the Borg scale revealed no statistical significant effect for the group receiving resistive breathing. BELMAN et al. [63] showed that similar workloads were obtained during resistive breathing and threshold loading. Threshold loading, however, enhances velocity of inspiratory muscle shortening and thus will shorten inspiratory time [54]. This allows more time for exhalation and might reduce dynamic hyperinflation [64]. The increased relaxation time might prevent the development of inspiratory muscle fatigue [65]. Furthermore, threshold loading significantly increased peak inspiratory flow rate [42]. This might have clinical relevance for patients with severe COPD who are 
not able to generate adequate flow to secure optimal lung deposition of inhaled medication. Finally, inspiratory pressure during resistive loading is flow dependent [43]. Since this is not the case for threshold loading [66], the latter device is preferred, especially for unsupervised training at home.

Training intensity varied among studies from $30 \%$ of $P_{\mathrm{I}}$,max $[50,51,53]$ up to $50-80 \%$ of $P_{I}$ max $[45,53,55]$. We did not observe a dose-response relationship, probably because inclusion of studies in the meta-analysis was set at an inspiratory load of $\geqslant 30 \% P$ I,max.

\section{Does IMT add to a general exercise training programme?}

IMT, when added to a GER programme, had an additional effect on inspiratory muscle strength and endurance, but not on dyspnoea (Borg score and CRQ scale). Similar to the effects observed during IMT alone, no additional effect was found on measures of maximal exercise capacity (Wmax, $V^{\prime} E$, max and $\left.V^{\prime} \mathrm{O}_{2}, \max \right)$. These conclusions are at variance with the analysis of O'BRIEN et al. [20], who observed a significant increase in maximal exercise tidal volume, but not on inspiratory muscle endurance. In the present meta-analysis, the additional effect of IMT to GER on functional exercise capacity just failed to reach statistical significance in patients with inspiratory muscle weakness. However, the observed strong trend in the present analysis, including two more studies, was stronger than in our previous meta-analysis [21]. It has face validity to consider that patients limited in their exercise performance by ventilatory constraints and dyspnoea due to inspiratory muscle weakness might indeed benefit from additional IMT. However, this hypothesis has to be investigated in a randomised controlled trial. Furthermore, inspiratory muscle fatigue reflexively induces sympathetically mediated vasoconstrictor activity, thereby compromising blood flow to the active limb muscles [67]. In turn, blood flow and oxygen transport to the working muscle are reduced, thereby exacerbating limb fatigue and compromising exercise performance [68]. Further research has to provide evidence that IMT indeed reduces the onset of respiratory muscle "fatigue", and thereby improves exercise performance.

\section{Which COPD patient will benefit from IMT?}

In the present analysis we observed that patients with inspiratory muscle weakness, defined as $P_{\mathrm{I}, \max }<60 \mathrm{cmH}_{2} \mathrm{O}$, were more likely to improve inspiratory muscle strength and functional exercise performance when IMT was applied in addition to GER. In addition, studies including patients with a low baseline $\mathrm{Pa}, \mathrm{O}_{2}$ or high baseline $\mathrm{Pa}, \mathrm{CO}_{2}$ had more improvement in inspiratory muscle strength achieved by IMT (fig. S3 in the online supplementary material). Indeed, inspiratory muscle weakness is associated with hypercapnia [3] and nocturnal desaturation [6], while IMT improved nocturnal desaturation significantly [48]. Improvement of dyspnoea was a persistent finding in the present study. The increased relative work of breathing is indicated by the high $P \mathrm{I} / P_{\mathrm{I}}$,max ratio, which is related to the perceived dyspnoea sensation [9]. IMT will increase PI,max, reduce subsequently the $P_{\mathrm{I}} / P_{\mathrm{I}}$ max ratio and thus dyspnoea sensation. Therefore, especially patients with high levels of dyspnoea might benefit from IMT.

Since most studies show loss of training effects on the long term, patients should be encouraged to continue with the IMT.
One study showed that the long-term benefits were maintained only when the IMT was continued [69].

\section{Conclusion}

In conclusion, IMT is an effective treatment modality in COPD patients to improve respiratory muscle strength and endurance, resulting in reductions of dyspnoea and improvement in functional exercise capacity and HRQoL. Patients with more advanced muscle weakness seem to be better responders, especially when considering IMT in addition to general exercise training. Inspiratory muscle endurance training was shown to be less effective than respiratory muscle strength training.

\section{SUPPORT STATEMENT}

All authors wish to declare financial support for the submitted work from FWO-Vlaanderen Grant G 0523.06 and the Dutch Institute of Allied Health Care, Amersfoort, the Netherlands.

\section{STATEMENT OF INTEREST}

A statement of interest for M. Decramer can be found at www.erj. ersjournals.com/site/misc/statements.xhtml

\section{ACKNOWLEDGEMENTS}

We would like to thank J.L. Larson, S.E. Covey, S.F. Hsiao, R.J. Koppers, M.J. Mador, P. Cejudo Ramos (data from SÁnCHEZ RIERA et al., 2001), T.A. Scherer, C. Ho (data from SYKES, 2005) and V. Bustamante Madariaga for providing additional data for the meta-analyses.

\section{REFERENCES}

1 Decramer M, Demedts M, Rochette F, et al. Maximal transrespiratory pressures in obstructive lung disease. Bull Eur Physiopathol Respir 1980; 16: 479-490.

2 Polkey MI, Kyroussis D, Hamnegard CH, et al. Diaphragm strength in chronic obstructive pulmonary disease. Am J Respir Crit Care Med 1996; 154: 1310-1317.

3 Begin P, Grassino A. Inspiratory muscle dysfunction and chronic hypercapnia in chronic obstructive pulmonary disease. Am Rev Respir Dis 1991; 143: 905-912.

4 Killian KJ, Jones NL. Respiratory muscles and dyspnea. Clin Chest Med 1988; 9: 237-248.

5 Hamilton N, Killian KJ, Summers E, et al. Muscle strength, symptom intensity, and exercise capacity in patients with cardiorespiratory disorders. Am J Respir Crit Care Med 1995; 152: 2021-2031.

6 Heijdra YF, Dekhuijzen PN, Van Herwaarden CL, et al. Nocturnal saturation and respiratory muscle function in patients with chronic obstructive pulmonary disease. Thorax 1995; 50: 610-612.

7 Gosselink R, Troosters T, Decramer M. Peripheral muscle weakness contributes to exercise limitation in COPD. Am J Respir Crit Care Med 1996; 153: 976-980.

8 Sinderby C, Spahija J, Beck J, et al. Diaphragm activation during exercise in chronic obstructive pulmonary disease. Am J Respir Crit Care Med 2001; 163: 1637-1641.

9 O'Donnell DE, Bertley JC, Chau LK, et al. Qualitative aspects of exertional breathlessness in chronic airflow limitation: pathophysiologic mechanisms. Am J Respir Crit Care Med 1997; 155: 109-115.

10 Polkey MI, Kyroussis D, Keilty SE, et al. Exhaustive treadmill exercise does not reduce twitch transdiaphragmatic pressure in patients with COPD. Am J Respir Crit Care Med 1995; 152: 959-964.

11 Levine S, Kaiser L, Leferovich J, et al. Cellular adaptations in the diaphragm in chronic obstructive pulmonary disease. $N$ Engl J Med 1997; 337: 1799-1806. 
12 Orozco-Levi M, Gea J, Lloreta JL, et al. Subcellular adaptation of the human diaphragm in chronic obstructive pulmonary disease. Eur Respir J 1999; 13: 371-378.

13 Levine S, Nguyen T, Kaiser LR, et al. Human diaphragm remodeling associated with chronic obstructive pulmonary disease: clinical implications. Am J Respir Crit Care Med 2003; 168: 706-713.

14 Nici L, Donner C, Wouters E, et al. American Thoracic Society/ European Respiratory society statement on pulmonary rehabilitation. Am J Respir Crit Care Med 2006; 173: 1390-1413.

15 Ries AL, Bauldoff GS, Carlin BW, et al. Pulmonary Rehabilitation: Joint ACCP/AACVPR Evidence-Based Clinical Practice Guidelines. Chest 2007; 131: 4S-42S.

16 Smith K, Cook D, Guyatt GH, et al. Respiratory muscle training in chronic airflow limitation: a meta-analysis. Am Rev Respir Dis 1992; 145: 533-539.

17 Lotters F, van Tol B, Kwakkel G, et al. Effects of controlled inspiratory muscle training in patients with COPD: a metaanalysis. Eur Respir J 2002; 20: 570-576.

18 Geddes EL, Reid WD, Crowe J, et al. Inspiratory muscle training in adults with chronic obstructive pulmonary disease: a systematic review. Respir Med 2005; 99: 1440-1458.

19 Geddes EL, O’Brien K, Reid WD, et al. Inspiratory muscle training in adults with chronic obstructive pulmonary disease: an update of a systematic review. Respir Med 2008; 102: 1715-1729.

20 O'Brien K, Geddes EL, Reid WD, et al. Inspiratory muscle training compared with other rehabilitation interventions in chronic obstructive pulmonary disease: a systematic review update. J Cardiopulm Rehabil Prev 2008; 28: 128-141.

21 Lötters F, van Tol B, Kwakkel G, et al. Effects of controlled inspiratory muscle training in patients with COPD: a metaanalysis. Eur Respir J 2002; 20: 570-576.

22 Pardy RL, Rochester DL. Respiratory muscle training. Semin Respir Med 1992; 13: 53-62.

23 Higgins JP, Thompson SG, Deeks JJ, et al. Measuring inconsistency in meta-analyses. BMJ 2003; 327: 557-560.

24 Cohen J. Statistical Power Analysis for the Behavioural Sciences, New York, Academic Press, 1972.

25 Beckerman M, Magadle R, Weiner M, et al. The effects of 1 year of specific inspiratory muscle training in patients with COPD. Chest 2005; 128: 3177-3182.

26 Bustamante Madariaga V, Gáldiz Iturri JB, Gorostiza Manterola A, et al. Comparación de 2 métodos de entrenamiento muscular inspiratorio en pacientes con EPOC [Comparison of 2 methods for inspiratory muscle training in patients with chronic obstructive pulmonary disease]. Arch Bronconeumol 2007; 43: 431-438.

27 Covey MK, Larson JL, Wirtz SE, et al. High-intensity inspiratory muscle training in patients with chronic obstructive pulmonary disease and severely reduced function. J Cardiopulm Rehabil 2001; 21: 231-240.

28 Di Mambro TR, Figueiredo PHS, Wanderley TR, et al. Inspiratory muscle training in chronic obstructive pulmonary disease: impact on quality of life, exercise intolerance, and dyspnea. Fisioterapia e Pesquisa [Physical Therapy and Research] 2007; 14: 65-71.

29 Hill K, Jenkins SC, Philippe DL, et al. High-intensity inspiratory muscle training in COPD. Eur Respir J 2006; 27: 1119-1128.

30 Hsiao SF, Wu YT, Wu HD, et al. Comparison of effectiveness of pressure threshold and targeted resistance devices for inspiratory muscle training in patients with chronic obstructive pulmonary disease. J Formos Med Assoc 2003; 102: 240-245.

31 Koppers RJ, Vos PJ, Boot CR, et al. Exercise performance improves in patients with COPD due to respiratory muscle endurance training. Chest 2006; 129: 886-892.

32 Larson JL, Covey MK, Wirtz SE, et al. Cycle ergometer and inspiratory muscle training in chronic obstructive pulmonary disease. Am J Respir Crit Care Med 1999; 160: 500-507.
33 Mador MJ, Deniz O, Aggarwal A, et al. Effect of respiratory muscle endurance training in patients with COPD undergoing pulmonary rehabilitation. Chest 2005; 128: 1216-1224.

34 Magadle R, McConnell AK, Beckerman M, et al. Inspiratory muscle training in pulmonary rehabilitation program in COPD patients. Respir Med 2007; 101: 1500-1505.

35 Ramirez-Sarmiento A, Orozco-Levi M, Guell R, et al. Inspiratory muscle training in patients with chronic obstructive pulmonary disease. Am J Respir Crit Care Med 2002; 166: 1491-1497.

36 Sánchez Riera H, Montemayor Rubio T, Ortega Ruiz F, et al. Inspiratory muscle training in patients with COPD: effect on dyspnea, exercise performance, and quality of life. Chest 2001; 120: 748-756.

37 Scherer TA, Spengler CM, Owassapian D, et al. Respiratory muscle endurance training in chronic obstructive pulmonary disease: impact on exercise capacity, dyspnea, and quality of life. Am J Respir Crit Care Med 2000; 162: 1709-1714.

38 Seron $\mathrm{P}$, Riedemann $\mathrm{P}, \mathrm{Munoz} \mathrm{S}$, et al. Efecto del entrenamiento muscular inspiratorio sobre la fuerza muscular y la calidad de vida en pacientes con limitación crónica del flujo aéreo. Ensayo clínico aleatorizado [Effect of inspiratory muscle training on muscle strength and quality of life in patients with chronic airflow limitation: a randomized controlled trial]. Arch Bronconeumol 2005; 41: 601-606.

39 Sykes K. Inspiratory muscle training in the treatment of chronic obstructive pulmonary disease: randomized controlled trial. Am J Recreation Ther 2005; 4: 39-48.

40 Weiner P, Magadle R, Berar-Yanay N, et al. The cumulative effect of long-acting bronchodilators, exercise, and inspiratory muscle training on the perception of dyspnea in patients with advanced COPD. Chest 2000; 118: 672-678.

41 Weiner $\mathrm{P}$, Magadle R, Beckerman M, et al. Comparison of specific expiratory, inspiratory, and combined muscle training programs in COPD. Chest 2003; 124: 1357-1364.

42 Weiner $\mathrm{P}$, Weiner M. Inspiratory muscle training may increase peak inspiratory flow in chronic obstructive pulmonary disease. Respiration 2006; 73: 151-156.

43 Belman MJ, Shadmehr R. Targeted resistive ventilatory muscle training in chronic obstructive pulmonary disease. J Appl Physiol 1988; 65: 2726-2735.

44 Berry MJ, Adair NE, Sevensky KS, et al. Inspiratory muscle training and whole-body reconditioning in chronic obstructive pulmonary disease. Am J Respir Crit Care Med 1996; 153: 1812-1816.

45 Dekhuijzen PN, Folgering HT, Van Herwaarden CL. Target-flow inspiratory muscle training during pulmonary rehabilitation in patients with COPD. Chest 1991; 99: 128-133.

46 Goldstein R, De Rosie J, Long S, et al. Applicability of a threshold loading device for inspiratory muscle testing and training in patients with COPD. Chest 1989; 96: 564-571.

47 Harver A, Mahler DA, Daubenspeck JA. Targeted inspiratory muscle training improves respiratory muscle function and reduces dyspnea in patients with chronic obstructive pulmonary disease. Ann Intern Med 1989; 111: 117-124.

48 Heijdra YF, Dekhuijzen PN, Van Herwaarden CL, et al. Nocturnal saturation improves by target-flow inspiratory muscle training in patients with COPD. Am J Respir Crit Care Med 1996; 153: 260-265.

49 Kim MJ, Larson JL, Covey MK, et al. Inspiratory muscle training in patients with chronic obstructive pulmonary disease. Nurs Res 1993; 42: 356-362.

50 Larson JL, Kim MJ, Sharp JT, et al. Inspiratory muscle training with a pressure threshold breathing device in patients with chronic obstructive pulmonary disease. Am Rev Respir Dis 1988; 138: 689-696.

51 Lisboa C, Villafranca C, Leiva A, et al. Inspiratory muscle training in chronic airflow limitation: effect on exercise performance. Eur Respir J 1997; 10: 537-542. 
52 Patessio A, Rampulla C, Fracchia C, et al. Relationship between the perception of breathlessness and inspiratory resistive loading: report on a clinical trial. Eur Respir J 1989; 2: Suppl. 7, 587s-591s.

53 Preusser BA, Winningham ML, Clanton TL. High- vs low-intensity inspiratory muscle interval training in patients with COPD. Chest 1994; 106: 110-117.

54 Villafranca C, Borzone G, Leiva A, et al. Effect of inspiratory muscle training with an intermediate load on inspiratory power output in COPD. Eur Respir J 1998; 11: 28-33.

55 Wanke T, Formanek D, Lahrmann $\mathrm{H}$, et al. Effects of combined inspiratory muscle and cycle ergometer training on exercise performance in patients with COPD. Eur Respir J 1994; 7: 22052211.

56 Weiner P, Azgad Y, Ganam R. Inspiratory muscle training combined with general exercise reconditioning in patients with COPD. Chest 1992; 102: 1351-1356.

57 Geddes EL, O'Brien K, Reid WD, et al. Inspiratory muscle training in adults with chronic obstructive pulmonary disease: an update of a systematic review. Respir Med 2008; 102: 1715-1729.

58 Puhan MA, Mador MJ, Held U, et al. Interpretation of treatment changes in 6-minute walk distance in patients with COPD. Eur Respir J 2008; 32: 637-643.

59 Holland AE, Hill CJ, Rasekaba T, et al. Updating the minimal important difference for six-minute walk distance in patients with chronic obstructive pulmonary disease 2. Arch Phys Med Rehabil 2010; 91: 221-225.
60 Witek TJ Jr, Mahler DA. Minimal important difference of the transition dyspnoea index in a multinational clinical trial. Eur Respir J 2003; 21: 267-272.

61 Leith DE, Bradley ME. Ventilatory muscle strength and endurance training. J Appl Physiol 1976; 41: 508-516.

62 Boutellier U, Piwko P. The respiratory system as an exercise limiting factor in normal sedentary subjects. Eur J Appl Physiol 1992; 64: 145-152.

63 Belman MJ, Warren CB, Nathan SD, et al. Ventilatory load characteristics during ventilatory muscle training. Am J Respir Crit Care Med 1994; 149: 925-929.

64 Petrovic M, Werner I, Reiter M, et al. Effects of inspiratory muscle training on dynamic hyperinflation in patients with COPD. Eur Respir J 2009; 34: 678s.

65 Bellemare F, Grassino A. Effect of pressure and timing of contraction on human diaphragm fatigue. J Appl Physiol 1982; 53: 1190-1195.

66 Gosselink R, Wagenaar RC, Decramer M. The reliability of a commercially available threshold loading device. Thorax 1996; 51: 601-605.

67 Dempsey JA, Amann M, Romer LM, et al. Respiratory system determinants of peripheral fatigue and endurance performance. Med Sci Sports Exerc 2008; 40: 457-461.

68 Harms CA, Wetter TJ, St Croix CM, et al. Effects of respiratory muscle work on exercise performance. J Appl Physiol 2000; 89: 131-138.

69 Weiner P, Magadle R, Beckerman M, et al. Maintenance of inspiratory muscle training in COPD patients: one year followup. Eur Respir J 2004; 23: 61-65. 